\title{
El tratamiento catalográfico de los mapas en las bibliotecas
}

Carmen Líter Mayayo, Jefe del Servicio de Cartografía, Biblioteca Nacional

Los materiales cartográficos son aquellos que representan total o parcialmente la Tierra o los cuerpos celestes a cualquier escala, como los mapas y planos, en dos y tres dimensiones, las cartas aeronáuticas, marinas y celestes, los globos, los bloque-diagramas, los cortes de terreno, las fotografias aéreas, los atlas, las vistas a vuelo de pájaro, las imágenes satélite, etcétera.

Los documentos cartográficos son materiales que desde hace muchos años se conservan en las bibliotecas, siendo objeto primordial su tratamiento bibliográfico, catalogación, clasificación y difusión. Estos documentos, además, están sujetos a la Ley de Depósito Legal. El Depósito Legal es la obligación, impuesta por ley, de depositar en una o varias agencias especificadas, ejemplares de las publicaciones de todo tipo, reproducidas en cualquier soporte, por cualquier procedimiento para distribución pública. La Biblioteca Nacional, así como las otras bibliotecas depositarias (bibliotecas públicas del Estado y bibliotecas autonómicas), reciben los materiales bibliográficos que se depositan en las oficinas que gestionan el Depósito Legal. En España se creó en 1957 y las publicaciones sujetas a esta obligación son libros, publicaciones periódicas, folletos, mapas y planos, música impresa y también materiales no librarios como vídeos analógicos, CD audio, disquetes, CD-ROM, DVD-ROM, DVD-vídeo, etcétera, editados en el territorio español. La descripción bibliográfica de los materiales cartográficos representa, dentro de los materiales denominados especiales, un capitulo aparte. Su tratamiento precisa además unos conocimientos igualmente especiales ya que hay que expresar escalas, proyecciones, coordenadas, equinoccios o interpretar gráficos, entre muchos otros aspectos. Aunque la exhaustividad de la descripción depende de la profundidad del conocimiento en estas áreas, siempre es conveniente contar con las herramientas adecuadas para enfrentarse a esta tarea con seguridad y precisión.

\section{DESCRIPCIÓN DEL MATERIAL CARTOGRÁFICO}

Los inicios de la catalogación de las publicaciones monográficas se remontan a la segunda mitad del siglo XVIII. Sin embargo, no sucede lo mismo con la catalogación de los materiales cartográficos. El origen de los materiales especiales como fondo de colección de las bibliotecas, si exceptuamos los centros históricos que conservan este tipo de documentos, es un fenómeno bastante reciente, pro- cede de las últimas décadas del siglo XIX. En España la aparición de las cartotecas, como centros especializados en el tratamiento, conservación y difusión de los documentos cartográficos, se remonta al primer tercio del siglo $X X$, aunque es en los últimos veinte años cuando los centros especializados en la conservación y difusión de la documentación cartográfica han experimentado un crecimiento importante. Los centros conservadores de mapas habitualmente dependen de bibliotecas, archivos, instituciones geográficas, militares, universidades y centros de documentación.

En general, el tratamiento y catalogación de los materiales cartográficos es bastante reciente. Hay algunos precedentes de normativa como la elaborada por la Universidad de Hertfordshire (1901) o el Map Department de la American Geographical Society (1902). En el año 1927 la Cambridge University Library publicó las primeras normas para materiales especiales, Rules for the Catalogues of Printed Books, Maps, and Music, en las que se establecía que las reglas para mapas no eran sustancialmente diferentes de la catalogación de libros, siendo el nombre de lugar la principal entrada para la descripción de fondos cartográficos.

En 1961 se celebró en París la International Conference of Cataloguing Principles donde se sentaron las bases de la catalogación descriptiva en las siguientes décadas. De esta reunión surgió la necesidad de publicar un código internacional aceptado por todos los países del mundo, para facilitar el intercambio de información bibliográfica. En esta línea, la American Association publica, en 1967, la primera edición de las reglas AACR (Anglo-American Cataloguing Rules), que dedican ya un capitulo a los documentos cartográficos: "Maps, relief models, globes and atlases". La segunda edición de estas normas, las AACR2, se publica en 1978 y tres años después, en 1981, fue adoptada por la Library of Congress, la National Library of Canada, la British Library y la Australian National Library.

A partir de los años 70 la International Federation of Library Associations (IFLA) publica las primeras normas generales de uso internacional, las ISBD (International Standard Bibliographic Description), que han desarrollado además reglas específicas para describir una amplia gama de materiales de bibliotecas. La primera en publicarse, en 1971, fue la ISBD(M) para monografías, como un conjunto de recomendaciones, que en 1973 será adoptada por varias bibliografías nacionales. El año 1977 aparecen las 
ISBD(CM), normas de descripción de los documentos cartográficos, cuya traducción al español se editó en Madrid en 1993.

En el año 2007 se publica la edición consolidada de las ISBD que reemplaza a las siete ISBD especializadas que se habian editado por separado (monografias, monografias antiguas, materiales cartográficos, publicaciones seriadas, recursos electrónicos, materiales no librarios y música impresa). La estructura ha cambiado para integrar la descripción de todo tipo de recursos, y se ha proporcionado más coherencia entre las estipulaciones para la catalogación de los diferentes recursos. Las normas ISBD(CM) han sido la base de la catalogación del material cartográfico en los últimos veinte años.

En España hasta el año 1988 no se publican unas reglas específicas para la descripción de los materiales cartográficos, casi cien años después de los primeros intentos de normativa para la catalogación de publicaciones monográficas que se remontan a la segunda mitad del siglo XVIII. En 1902, se publica el que ha sido considerado el primer código español titulado, Instrucciones para la redacción de los catálogos en las Bibliotecas Públicas del Estado, normas de las que se han hecho diversas ediciones y modificaciones. Después de la Reunión Internacional de Catalogación, organizada por la IFLA (Copenhague, 1969) en la que se acordó establecer unas reglas internacionales para la descripción bibliográfica y así facilitar un intercambio mecanizado de la información, surgen las nuevas Reglas de Catalogación españolas. En 1985 se publica el primer volumen dedicado a Monografias y Publicaciones Seriadas; y en 1988 aparece el segundo volumen dedicado a la catalogación de los Materiales especiales, aquellos documentos que exigen para su descripción bibliográfica ciertas reglas que hagan mención de las características que los distinguen, ya sea en cuanto a su especial contenido o al soporte en que se encierra la información que se pretende catalogar.

Estas reglas recogen todos los avances producidos, hasta la fecha de su publicación, en el campo de la descripción bibliográfica de los materiales especiales. Para ello, se estudiaron no sólo las distintas normas ISBD, sino también las adaptaciones que de estas reglas internacionales estaban siendo utilizadas por las grandes bibliotecas de Occidente. A partir de este año todas las ediciones de las reglas contemplan la descripción de los materiales cartográficos, tanto la edición refundida y revisada de las Reglas de Catalogación, publicada en 1995, como sus reimpresiones de 1995, 1996 y 1999. Las reglas de catalogación para materiales cartográficos publicadas en España supusieron un gran avance en el desarrollo de la descripción de estos materiales. En general, respetan las normas de la descripción bibliográfica, si bien en algunos momentos hay diferencias y particularidades propias de este tipo de material.

A partir de enero de 2010 la Biblioteca Nacional de España empieza a utilizar la ISBD consolidada para la descripción, puesto que está más actualizada, y las Reglas de Catalogación (edición nuevamente revisada de 1999, reimpresión de 2010) de la que se siguen utilizando los capitulos relacionados con forma y elección de los puntos de acceso. Esta decisión se ha llevado a cabo ante los cambios internacionales que se están produciendo y que dificultan por el momento adoptar unas nuevas reglas. En cualquier caso, se sigue muy de cerca lo que se está haciendo en estos momentos y estableciendo acuerdos con otros paises para trabajar en coordinación, no duplicar esfuerzos y tomar la decisión oportuna en el momento oportuno.

\section{FORMATO DE DATOS}

En la Biblioteca Nacional, desde el año 1984, se lleva a cabo una amplia labor que comprende el estudio de las diferentes normativas internacionales, para la preparación de las nuevas ediciones de las Reglas de Catalogación y de los formatos IBERMARC (Registros bibliográficos, Autoridades y Fondos y Localizaciones).

A partir de noviembre de 2007 la Biblioteca Nacional de España cambió del formato IBERMARC al MARC 21. Como consecuencia del cambio y para poder ajustar al máximo el formato MARC 21 a las necesidades existentes, la Biblioteca está estudiando las diferencias más importantes que existen entre los dos formatos (IBERMARC-MARC 21) y las posibilidades de implementar nuevos campos, subcampos, códigos, etcétera, que nos acerquen más al que se ha estado utilizando hasta hace poco. Las propuestas relativas a estos cambios se han estado trabajando con el comité encargado de las mismas y se continúan desarrollando. Por otra parte la BNE sigue las normas internacionales, tanto en la descripción bibliográfica, ISBD y en el uso del formato MARC 21, como en los metadatos Dublin Core, juego de caracteres UNICODE y en los protocolos de transferencia de información.

\section{Bibliografía}

DÍEZ CARRERA, C. (coord.) (1998) Los materiales especiales en las bibliotecas. Gijón: Trea, 1998 (Biblioteconomía y administración cultural; 22)

DÍEZ CARRERA, C. (coord.) (2005) La catalogación de los materiales especiales. Gijón: Trea, [2005] (Biblioteconomía y administración cultural; 120) INTERNATIONAL Standard Bibliographic Description: (ISBD). Preliminary consolidated ed. München: Saur, 2007 (IFLA series on bibliographic control; v. 31) ISBD(CM): descripción bibliográfica internacional normalizada para material cartográfico. Ed. rev. Madrid: ANABAD: Arco Libros, D. L. 1993 (Colección Normas) JIMÉNEZ PELAYO, J.; MONTEAGUDO LÓPEZ-MENCHERO, J. (ed.) (2001) La Documentación cartográfica: Tratamiento, gestión y uso. [Huelva]: Universidad de Huelva, Servicio de Publicaciones, [2001] (Instrumenta studiorum; 7)

LíTER MAYAYO, C.; GARCÍA CALATAYUD, C. (1999) Materiales cartográficos. Manual de catalogación. Madrid: Arco Libros, 1999 NORMAS y estándares bibliográficos [en línea]. Madrid: Biblioteca Nacional de España, $2010<$ http://www.bne.es/es/Servicios/NormasEstandares> [Consulta: noviembre 2010]

REGLAS de catalogación. Madrid: Ministerio de Educación y Cultura, Centro de Publicaciones: Boletín Oficial del Estado, 1999 